\title{
Post-operative Complications of Fascia Lata Brow Suspension Surgery for Blepharoptosis
}

Nesa $Z^{1 *}$, Ahmed AHMK ${ }^{2}$

\author{
Tabun Nesa, Assistant Professor, Department of Opthalmology, Abdul Malek Ukil Medical College, Naokhali, Bangladesh \\ ${ }^{2}$ Abu Hena Mostafa Kamal Ahmed, Assistant Professor, Department of Opthalmology, Shaheed Ziaur Rahman Medical College, \\ Bogura, Bangladesh
}

DOI: $10.36347 /$ sjams.2021.v09i03.010

| Received: 16.12.2020 | Accepted: 26.12.2020 | Published: 05.03.2021

*Corresponding author: Zabun Nesa

\section{Abstract}

Original Research Article

Introduction: Blepharoptosis or drooping of the upper eyelid is a common ophthalmic problem found in all age groups. It has multiple causes. Harvesting fascia lata was reported to cause minimal or no postoperative morbidity though complications can arise when a large area of fascia lata is removed. Very few complications related to harvesting fascia lata for ptosis surgery have been reported. Problems with postoperative infections and haematomas are cited. Aim of the study: To assess the post-operative complications after fascia lata brow suspension surgery for blepharoptosis. Material \& Methods: This prospective observational study was conducted on 30 consecutive patients of $\leq 4 \mathrm{~mm}$ ptosis with poor LPS function in the dept. of Oculoplasty, NIO \& H, Dhaka during the period of January 2009 to December 2009. Patients were surgically treated with frontalis brow suspension with harvested Fascia lata according to the following exclusion and inclusion criteria. Data were analyzed by appropriate tests. Sampling technique was non-randomized and purposive. Study patients were explained in details about the disease process, benefits of evaluation, methods and risks of evaluation techniques and then written consent were taken before conducting the study maintaining the principles of Helsinki declaration. Results: Mean age was $21.53 \pm 10.27$ (SD) years with age ranged from 5 years to 45 years. Out of 30 cases, $17(56.7 \%)$ were male and $13(43.3 \%)$ were female. $19(63.3 \%)$ cases were congenital ptosis, $05(16.7 \%)$ cases were Blepharophimosis, $3(10 \%)$ cases were third nerve palsy and $3(10 \%)$ cases were Chronic progressive external ophthalmoplegia (CPEO). 03 (10\%) cases developed haematoma formation, $01(3.33 \%)$ case developed muscle herniation, $05(16.67 \%)$ cases developed disturbance in walking and limping, $01(3.33 \%)$ case developed wound infection and $02(6.67 \%)$ cases developed ugly scar. Conclusion: The current study showed that frontalis brow suspension surgery with harvested fascia lata for the patients of $\leq 4 \mathrm{~mm}$ ptosis with poor LPS function yields highly satisfactory functional result with minimal complications post-operatively at the harvesting wound as well as at the ptosis correction site.

Keywords: Blepharoptosis, Fascia lata, Complications, Surgery, Ophthalmic.

Copyright $\odot 2021$ The Author(s): This is an open-access article distributed under the terms of the Creative Commons Attribution 4.0 International License (CC BY-NC 4.0) which permits unrestricted use, distribution, and reproduction in any medium for non-commercial use provided the original author and source are credited.

\section{INTRODUCTION}

Blepharoptosis or drooping of the upper eyelid is a common ophthalmic problem found in all age groups. It has multiple causes. Many, but not all, types of blepharoptosis are treated surgically. There are three classic surgical procedures for the treatment of ptosis: frontalis suspension, levator resection, and Müller muscle-conjunctival resection. There are variations on the execution and materials used for each of these procedures, but basic principles hold true within each category. Which type of surgical procedure, if any, is appropriate for a given patient's ptosis is determined by the cause and extent of the ptosis [1,2]. The basic principle of the frontalis suspension is to use the frontalis muscle to elevate the eyelids. Many surgical techniques and sling configurations have been described
$[1,3]$. Autogenous fascia lata is commonly used as the material of choice for the frontalis sling in brow suspension ptosis surgery in patients over 3 years of age. Many surgeons for its predictable and lasting results preferred it. Autogenous material avoids the problems associated with both donor human tissue and synthetic materials such as granuloma formation, infection, extrusion, and late failure [4-8]. Harvesting fascia lata was reported to cause minimal or no postoperative morbidity though complications can arise when a large area of fascia lata is removed. Very few complications related to harvesting fascia lata for ptosis surgery have been reported. Problems with postoperative infections and haematomas are cited. Under correction of a ptotic lid is the most common complication. Overcorrection in a patient with acquired 
ptosis, particularly levator dehiscence, is rather easy to produce if a levator resection is performed rather than simply a repair of the dehiscence. Usually, postoperative diplopia is due to direct damage to the superior rectus muscle and sometimes the superior oblique muscle; rarely, it is due to direct nerve damage. These situations can usually be avoided by careful preoperative evaluation and careful surgery. Particularly in congenital ptosis, when factors inherent to the anatomic defect pose limitations to the surgical results, the expectations and goals of the surgery must be discussed carefully with the patient and/or the parents preoperatively. A defective levator muscle, whose function is abnormal or absent preoperatively, cannot be restored surgically. The lid level can be changed, but dynamic limitations of the affected muscle persist postoperatively, and these may result in significant lid lag and lagophthalmos. Often the best result that can be hoped for is a normal lid level and contour when the eyes are in the primary position.

\section{Methodology and Materials}

This prospective observational study was conducted on 30 consecutive patients of $\leq 4 \mathrm{~mm}$ ptosis with poor LPS function in the dept. of Oculoplasty, NIO \& H, Dhaka during the period of January 2009 to December 2009. Patients were surgically treated with frontalis brow suspension with harvested fascia lata according to the following exclusion and inclusion criteria. Patients were followed for 6 months' period to observe intra and post-operative complications related to harvesting wound and ptosis surgery site. Patients less than 15 years of age were anesthetized by administration of general anesthesia. In other patients, local anesthesia was used and monitoring by an anesthesiologist. In patients where surgery was done under local anesthesia, they were sedated ten minutes before the surgery. Afterwards, $4 \mathrm{ml}$ of lignocaine $2 \%$ with adrenaline was injected sub muscularly in upper lid to ensure that proper informed written consent was taken. The hospital record was checked and only after that anesthesia was administered. In all of the patients, two skin incisions $1 \mathrm{~cm}$ in length and $10 \mathrm{~cm}$ apart were made on the temporal aspect of the thigh after general anesthesia. Identification of the fascia was made by its white glistening appearance and parallel fibers. When the dissection and decollation over and below the fascia was well completed, two longitudinal cuts parallel to each other were made on the length of the fascia and finally a transverse cut was made on its distal end and about $12 \mathrm{~cm}$ of fascia, $1-1.5 \mathrm{~cm}$ in width was removed. We divided the fascia longitudinally into four or two equal strips and at the end of the procedure sutured the leg incisions with 4-0 absorbable suture subcutaneously and 5-0 nylon suture for skin. Data were collected in a pre-designed data collection sheet and were analyzed by appropriate tests. Sampling technique was nonrandomized and purposive. Study patients were explained in details about the disease process, benefits of evaluation, methods and risks of evaluation techniques and then written consent were taken before conducting the study maintaining the principles of Helsinki declaration.

Inclusion Criteria: Patients with blepharoptosis -

- Age 5-60 years

- $\quad$ Either sex

- $\quad$ Ptosis $\leq 4 \mathrm{~mm}$

- Poor LPS function

Exclusion Criteria: Patients beyond the selected age group, adults unfit for general anaesthesia, patients unwilling to have fascia lata harvesting.

\section{RESUltS}

In this study, age distribution of 30 study subjects show that age ranged from 5 years to 45 years with a mean age $21.53 \pm 10.27$ (SD) years (Figure I). Out of 30 cases, $17(56.7 \%)$ were male and $13(43.3 \%)$ were female (Figure II). Types of ptosis among study subjects reflects that out of 30 cases, $19(63.3 \%)$ cases were congenital ptosis, $05(16.7 \%)$ cases were Blepharophimosis, $3(10 \%)$ cases were third nerve palsy and $3(10 \%)$ cases were Chronic progressive external ophthalmoplegia (CPEO) (Figure III). Distribution of amount of ptosis show that out of 30 cases, 13 (43.3\%) had $3 \mathrm{~mm}$ ptosis, $09(30 \%)$ had $3.5 \mathrm{~mm}$ ptosis and 08 $(26.7 \%)$ cases had $4 \mathrm{~mm}$ ptosis. Mean ptosis was $3.41 \pm$ 0.41 (SD) $\mathrm{mm}$ (Table I). Distribution of complications related to harvesting wound show that out of 30 cases, $03(10 \%)$ cases developed haematoma formation, 01 (3.33\%) case developed muscle herniation, 05 (16.67\%) cases developed disturbance in walking and limping, 01 $(3.33 \%)$ case developed wound infection and 02 $(6.67 \%)$ cases developed ugly scar (Table II). Distribution of complication related to ptosis correction show that out of 30 cases, 04 (13.33\%) cases developed under-correction, $01 \quad(3.33 \%)$ case developed overcorrection, $02(6.67 \%)$ cases developed corneal abrasion, $02(6.67 \%)$ cases developed peaking of the lid, $01(3.33 \%)$ case developed lid lag, 01 (3.33\%) case developed exposure keratopathy; but no cases developed diplopia. In the current study, complete cosmetic success was achieved in $25(83.33 \%)$ cases and no recurrence was observed in 6 months follow up (Table III). 


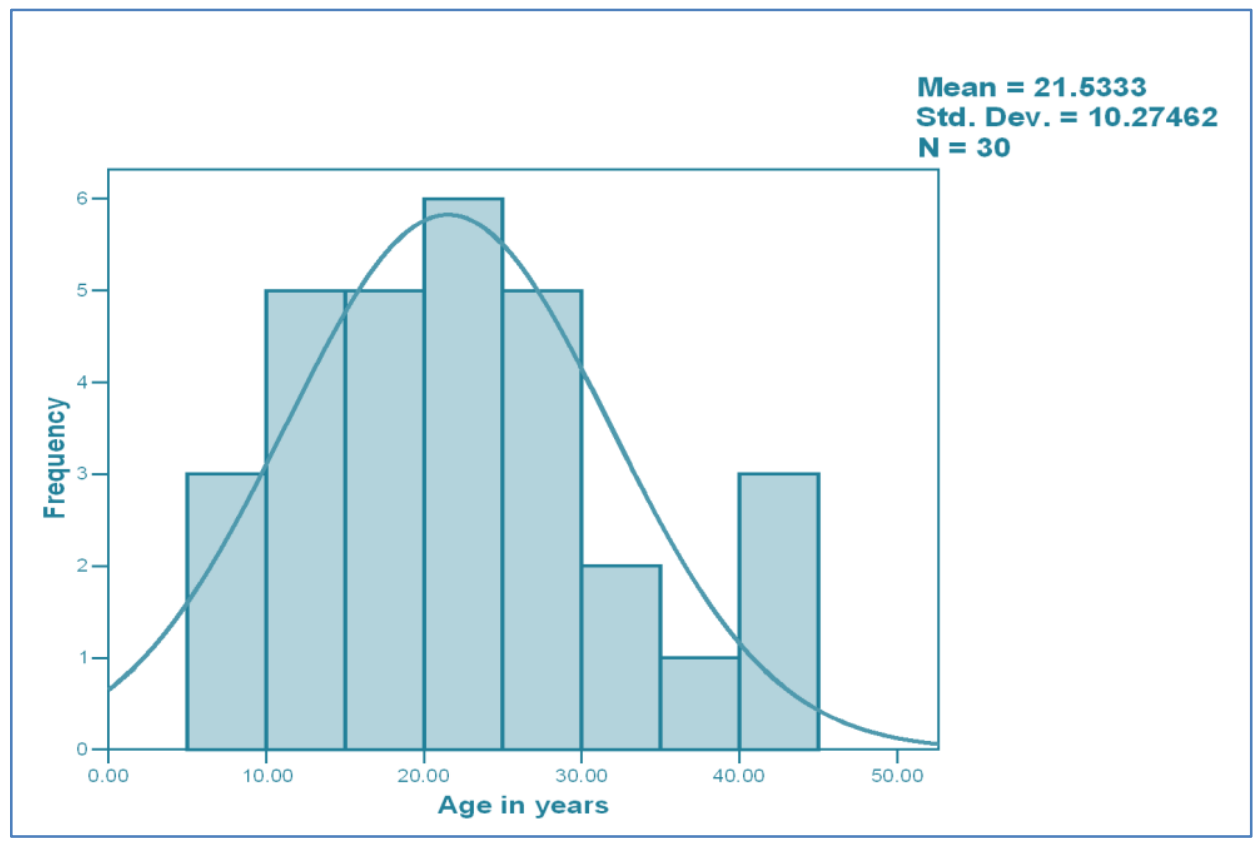

Fig-I: Histogram showing age distribution of study subjects

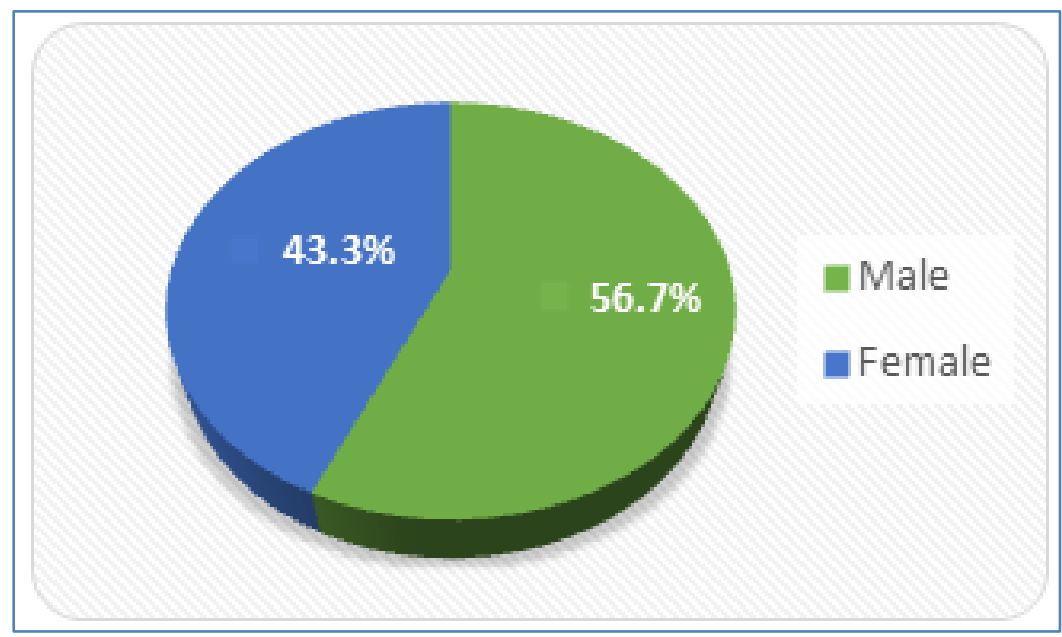

Fig-II: Pie chart showing sex distribution of study subject

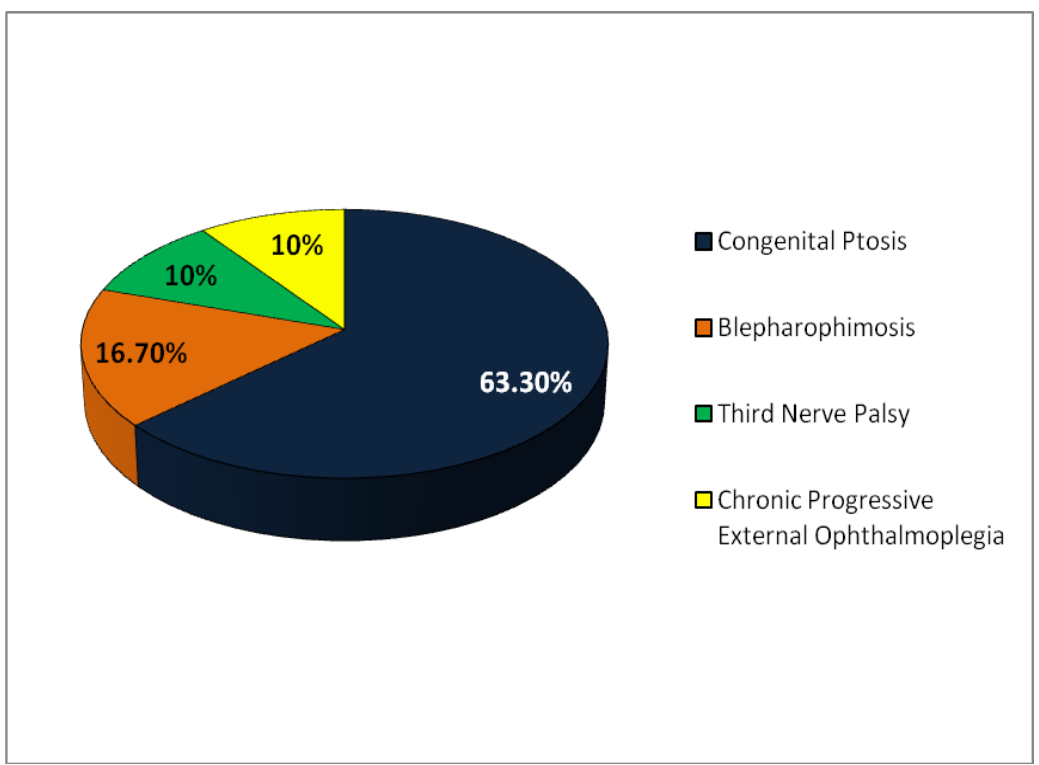

Fig-III: Pie chart showing types of ptosis 
Table-I: Distribution of amount of ptosis

\begin{tabular}{|l|l|c|}
\hline Amount of ptosis & No. of cases (\%) & Mean value \pm SD \\
\hline $3 \mathrm{~mm}$ & $13(43.3)$ & \\
\cline { 2 - 2 } $.5 \mathrm{~mm}$ & $9(30)$ & \\
\cline { 1 - 2 } $\mathrm{mm}$ & $8(26.7)$ & \\
\hline
\end{tabular}

Table-II: Complications related to harvesting wound

\begin{tabular}{|l|l|}
\hline Name of complication & No. of cases (\%) \\
\hline Haematoma formation & $03(10)$ \\
\hline Muscle herniation & $01(3.33)$ \\
\hline Disturbance in walking and limping & $05(16.67)$ \\
\hline Wound infection & $01(3.33)$ \\
\hline Ugly scar & $02(6.67)$ \\
\hline
\end{tabular}

Table-III: Complication related to ptosis correction

\begin{tabular}{|l|l|}
\hline Name of complication & No. of cases (\%) \\
\hline Undercorrection & $04(13.33)$ \\
\hline Overcorrection & $01(3.33)$ \\
\hline Corneal abrasion & $02(6.67)$ \\
\hline Peaking of the lid & $02(6.67)$ \\
\hline Lid lag & $01(3.33)$ \\
\hline Exposure keratopathy & $01(3.33)$ \\
\hline Diplopia & 00 \\
\hline
\end{tabular}

\section{Discussion}

In the present study, age distribution of 30 study subjects was ranged from 5 years to 45 years with a mean age $21.53 \pm 10.27$ (SD) years. Bleyen et al. [9] evaluated the long-term results of frontalis suspension by harvesting of autogenous fascia lata for in ptosis correction. In their case, series mean age of the patients was 7 years (range, 1-15). Though Crawford [4] mentioned that best ages for surgery is between 3-1/2 and 6 years of age, in Bangladesh, these patients consult with ophthalmologists at relatively older age due to some superstitions; in some cases, lack of awareness and lack of facilities are also responsible. Out of 30 cases, $17(56.7 \%)$ were male and $13(43.3 \%)$ were female. Wheatcroft et al. [10] reported in their study $48 \%$ male and $52 \%$ female ptosis patients. In case of the types of ptosis among study subjects, 19 (63.3\%) cases were congenital ptosis, $05(16.7 \%)$ cases were Blepharophimosis, three $(10 \%)$ cases were third nerve palsy and three $(10 \%)$ cases were chronic progressive external ophthalmoplegia (CPEO). Esmaeli et al. [11] studied the long-term rate of recurrence of ptosis and other postoperative complications after frontalis suspension. In the present study, the distribution of amount of ptosis, $13(43.3 \%)$ had $3 \mathrm{~mm}$ ptosis, 09 (30\%) had $3.5 \mathrm{~mm}$ ptosis and $08(26.7 \%)$ cases had 4 $\mathrm{mm}$ ptosis. Mean ptosis was $3.41 \pm 0.41(\mathrm{SD}) \mathrm{mm}$. Wheatcroft et al. [10] conducted a study on ptosis patients having ptosis of $\leq 4 \mathrm{~mm}$; this is similar to the current study. In our study, we observed that the distribution of complications related to harvesting wound. Where among 30 cases, 03 (10\%) cases developed haematoma formation, 01 (3.33\%) muscle herniation, $05(16.67 \%)$ disturbance in walking and limping, $01(3.33 \%)$ wound infection and 02 (6.67\%) ugly scar. Wheatcroft et al. [10] conducted a study with the aim to assess the morbidity associated with harvesting autogenous fascia lata for brow suspension ptosis surgery. Leibovitch et al. [12] reported $11.1 \%$ patients with a hypertrophied leg scar. Bleyen et al.[9] reported that $26.7 \%$ patients had obviously visible bulged scar; the mean width of the scar was $7.5 \mathrm{~mm}$, and the mean length was $3.6 \mathrm{~cm}$. Regarding the distribution of complications related to ptosis correction, $04(13.33 \%)$ cases developed undercorrection, 01 (3.33\%) over-correction, 02 (6.67\%) corneal abrasion, $02(6.67 \%)$ peaking of the lid, 01 $(3.33 \%)$ lid lag, 01 (3.33\%) exposure keratopathy; but no cases developed diplopia. Yoon and Lee [13] assessed long-term functional and cosmetic outcomes after frontalis suspension using fascia lata autografts for congenital ptosis in Asian children. Whitehouse et al. [14] conducted a study to determine the visual and cosmetic outcome following the surgical correction of isolated congenital ptosis.

\section{Limitations of THE STUDY}

The study period was very short due to time constrained. In addition, the sample size was comparatively small. Therefore, the findings may not reflect the scenario of the whole country.

\section{Conclusion and Recommendations}

Ptosis surgery seems to be easy but difficult to perform and hard to satisfy. In the result of the current 
study shows that frontalis brow suspension surgery with harvested fascia lata for the patients of $\leq 4 \mathrm{~mm}$ ptosis with poor LPS function yields highly satisfactory functional result with minimal complications postoperatively at the harvesting wound as well as at the ptosis correction site. So that, this study recommends that frontalis brow suspension surgery with harvested fascia lata for the patients of $\leq 4 \mathrm{~mm}$ ptosis with poor LPS function is a safe and effective procedure provided the surgery is done very skillfully and maintaining proper technique.

\section{Funding}

No funding sources

\section{Conflict of interest}

None declared

\section{Ethical approval}

The study was approved by the Institutional Ethics Committee

\section{REFERENCES}

1. Putterman AM basic oculoplastic surgery. In: Principles and Practice of Ophthalmology, Volume 3. Edited by Peyman D, Sanders D, and Goldberg MF. Philadelphia: WB Saunders. 1980:2246-2333.

2. Shields M, Putterman AM. Blepharoptosis correction. Current Opinion in Otolaryngology \& Head and Neck Surgery. 2003, 11:261-266.

3. Stewart WB: Ophthalmology Monographs Number Eight Surgery of the Eyelid, Orbit, and Lacrimal System, vol 2. San Francisco: American Academy of Ophthalmology. 1994:84-133.

4. Crawford JS. Repair of ptosis using frontalis muscle and fascia lata: a 20-year review. Ophthalmic Surg. 1977; 8:31-40.
5. Wagner RS, Mauriello Jr JA, Nelson LB, Calhoun $\mathrm{JH}$, Flanergan JC, Harley RD. Treatment of congenital ptosis with frontalis suspension: a comparison of suspensory materials. Ophthalmology. 1984; 91:245-8.

6. Wilson ME, Johnson RW. Congenital ptosis, longterm results of treatment using lyophilized fascia lata for frontalis suspensions. Ophthalmology. 1991; 98:1234-7.

7. Crawford JS, Doucet TW. Uses of fascia in ophthalmology and the benefits of autogenous sources. J Pediatr Ophthalmol Strabismus. 1982; 19:21-5.

8. Fox SA. Complications of frontalis sling surgery. Am J Ophthalmol. 1967; 63:758-62.

9. Bleyen I, Hardy I, Codère F. Muscle prolapse after harvesting autogenous fascia lata used for frontalis suspension in children. Ophthal Plast Reconstr Surg. 2009 Sep-Oct; 25(5):359-60.

10. Wheatcroft SM, Vardy SJ, Tyers AG. Complications of fascia lata harvesting for ptosis surgery. British Journal of Ophthalmology. 1997; 81:581-583 581 .

11. Esmaeli B, Chung H, Pashby RC. Long-term results of frontalis suspension using irradiated, banked fascia lata. Ophthal Plast Reconstr Surg. 1998 May; 14(3):159-63.

12. Leibovitch I, Leibovitch L, Dray JP. Long-term results of frontalis suspension using autogenous fascia lata for congenital ptosis in children under 3 years of age. Am J Ophthalmol.2003 Nov; 136(5):866-71.

13. Yoon JS, Lee SY. Long-term functional and cosmetic outcomes after frontalis suspension using autogenous fascia lata for pediatric congenital ptosis. Ophthalmology. 2009 Jul; 116(7):1405-14.

14. Whitehouse GM, Grigg JR, Martin FJ. Congenital ptosis: results of surgical management. Aust N Z J Ophthalmol.1995 Nov; 23(4):309-14. 